\title{
The Application of Multiple Criteria Decision Making/Aiding Methodology in the Evaluation and Redesign of Logistics Systems
}

\author{
Jacek Żak*
}

\begin{abstract}
The paper presents the methodological background of Multiple Criteria Decision Making/Aiding (MCDM/A) and its practical application in logistics systems. It explains why MCDM/A methodology is important when dealing with different categories of decision problems that arise in those systems. The major features and basic notions of MCDM/A methodology are presented, while different categories of MCDM/A methods are characterized and classified. Two case studies demonstrate potential applications of MCDM/A methodology in logistics. In the first case study multiple objective optimization of the distribution system is carried out and compared with single objective optimization. The decision problem is formulated as multiple criteria mathematical programming problem and solved by an extended version of MS Excel Solver - Premium Solver Plus. The second case study focuses on multiple criteria evaluation and the ranking of logistics infrastructure objects, i.e. a set of warehouses - distribution centres. The decision problem is formulated as a multiple criteria ranking problem and solved with an application of the ELECTRE III/IV method.
\end{abstract}

Keywords: logistics systems, multiple criteria optimization \& evaluation, MCDM/A methodology

Mathematics Subject Classification: 90B50, 68U35, 91B06

Submitted: June 17, 2019

Revised: October 17, 2019

(C) 2019 Author. This is an open access publication, which can be used, distributed and reproduced in any medium according to the Creative Commons CC-BY 4.0 License. License requiring that the original work has been properly cited.

\section{INTRODUCTION}

One may quote many definitions of logistics and logistics systems (Coyle et al., 1996; McKinnon, 1989; Ross, 1996; Wegryn and Siprelle, 2001). Despite the variety of those definitions many authors (Coyle et al., 1996; Kopczak, 1997; Korpela and Lehmusvaara, 1999; McKinnon, 1989; Ross, 1996) would probably agree that logistics systems may be considered as complex operational systems that are responsible for storing, processing and moving materials / goods from their origins (fields, mines, sites) to their destinations (final consumers) in an organized and efficient way. In logistics systems,

\footnotetext{
* Poznan University of Technology, Faculty of Engineering Management, Institute of Logistics; e-mail: jacek.zak@put.poznan.pl
} 
raw materials are transformed into semi-finished products and those are processed and delivered in the form of finished goods to consumers for final consumption and / or utilization. Several major activities are carried out in logistics systems, including: material processing (manufacturing), warehousing, material handling and control (loading and unloading, packaging, inspecting), material shipping and transporting, material monitoring and returning to suppliers. The majority of logistics systems are organized as supply chains or supply networks, which can be divided into links representing respective suppliers and customers (Coyle et al., 1996; Kieffer and Novack, 1998; Kisperska-Moron, 1999; Kopczak, 1997). Logistics systems are composed of such elements as: logistics infrastructure (warehouses - logistics centres, depots, hubs, roads, harbours, airports, customs agencies, border crossings, logistics equipment storage equipment, feeders, belt conveyers), human resources, moving fleet (vehicles) planes, container ships, trucks, vans, fork lifts, business processes carried out in those systems and organizational rules that provide coordination and control over the above mentioned components (Coyle et al., 1996; McKinnon, 1989; Ross, 1996). There are many stakeholders that are interested in the efficient operations of logistics systems, including: suppliers and customers, employees, third party logistics service providers, local communities. In many cases the interests of those groups may be contradictory and a compromise solution must be found to satisfy them to a certain degree. In addition, due to the complexity of the logistics systems, many different aspects and characteristics must be considered in their analysis and evaluation, including technical, economical, social, safety, and environmental factors, etc. As a result many decision problems that arise in logistics systems have a multiple criteria character and thus, it is appropriate to apply the methodology of MCDM/A while solving them. Multiple Criteria Decision Making/Aiding (MCDM/A) is a mature yet still dynamically developing field which aims at giving the DM some tools in order to enable him/her to advance in solving a complex decision problem, where several - often contradictory - points of view must be taken into account (Figueira et al., 2005; Vincke, 1992; Żak, 2005). In contrast to classical techniques of operations research (Hillier and Lieberman, 2005), multiple criteria methods do not yield "objectively best" solutions, because it is impossible to generate such solutions which are simultaneously the best from all points of view. In these circumstances a notion of a compromise solution (Steuer, 1986; Vincke, 1992) that takes into account both the trade-offs between criteria and the DM's preferences, is much more rational. MCDM/A supports DMs in solving so called multiple criteria decision problems.

Several authors (Kisperska-Moron, 1999; Korpela and Lehmusvaara, 1999; Landers et al., 2000; Rouwenhorst et al., 2000; Zak et al., 2002) have reported their efforts to develop original and innovative concepts for warehouses, distribution networks and supply chains. Different models and methods have been applied to increase the efficiency of the material storage and movement within the logistics systems (Landers et al., 2000; Rouwenhorst et al., 2000; Van den Berg and Zijm, 1999). Both B. Rouwenchorst and others (Rouwenhorst et al., 2000) and J. Van den Berg (Van den Berg and Zijm, 1999) have presented a comprehensive review of warehouse design and management techniques. They have presented their classification and comparison, also indicating their overall impact on the efficiency of the logistics systems. In the metority of cases 
the restructuring of warehouses, distribution networks and supply chains has the market-oriented character (Korpela and Lehmusvaara, 1999; Landers et al., 2000; Rouwenhorst et al., 2000). It is focused on reduction of logistics costs and delivery time, improvement of the customer's service and increase of product availability and accessibility.

This paper presents the application of the MCDM/A methodology to different categories of the decision problems that arise in the logistics systems. The paper has an instructional character and presents the general features and basic notions of $\mathrm{MCDM} / \mathrm{A}$ methodology. At the same time it focuses on the analysis of two real world case studies in large - size logistics systems operating in Poland. In the first case study multiple criteria optimization of the distribution system of electro-technical equipment and components is carried out. The decision problem is formulated as a single- and bi-criteria mathematical programming problem. It is solved with the application of the extended version of MS Excel Solver - Premium Solver Plus. The result of the optimization process is the recognition of the optimal number and location of the warehouses in the distribution system combined with the definition of the service areas of each warehouse. The second case study focuses on the multiple criteria evaluation of the logistics infrastructure, i.e. certain number of warehouses that constitute Regional Distribution Centres (RDCs) delivering spare parts for the automobile industry. The evaluation of the RDCs is formulated as a multiple criteria ranking problem. A set of 11 warehouses is evaluated by a consistent family of criteria and finally ranked from the best to the worst. In the computational phase the $\mathrm{MCDM} / \mathrm{A}$ ranking method, based on the outranking relation, called ELECTRE III (Roy, 1990a; Roy, 1990b; Vincke, 1992) has been applied.

The paper is composed of 5 sections. The introduction presents the background to the topics considered, the objectives and the content of the paper. In Section 2, the principles of the MCDM/A methodology are presented and major characteristics of the selected decision-aiding methods are described. Section 3 is devoted to the formulation of the decision problems, presented as two case studies. Computational experiments followed by conclusions are presented in sections 4 and 5, respectively. The paper is completed by a list of references.

\section{THE METHODOLOGY OF MULTIPLE CRITERIA DECISION MAKING/ AIDING}

As presented in section 1 the methodology of MCDM/A supports DMs in solving, so called, multiple criteria decision problems, i.e. situations in which, having defined a set of actions/variants/solutions $\boldsymbol{A}$ and a consistent family of criteria $\boldsymbol{F}$ the DM tends to (Figueira et al., 2005; Vincke, 1992):

- determine the best subset of actions/variants/solutions in $\boldsymbol{A}$ according to $\boldsymbol{F}$ (choice problem),

- divide $\boldsymbol{A}$ into subsets representing specific classes of actions/variants/solutions, according to concrete classification rules (sorting problem),

- rank actions / variants / solutions in $\boldsymbol{A}$ from the best to the worst, according to $\boldsymbol{F}$ (ranking problem). 
The proposed definition lets us distinguish the following major categories of MCDM/A problems (Figueira et al., 2005; Vincke, 1992):

- choice problems,

- sorting problems,

- ranking problems.

As discussed earlier the multiple criteria decision problems considered in this paper in case studies 1 (optimization of the distribution system) and 2 (evaluation of the logistics infrastructure) are choice and ranking problems, respectively.

Based on the above quoted definition one can easily determine major components that exist in each formulation of the multiple criteria decision problem, i.e. a set of actions / variants / solutions $\boldsymbol{A}$ and a consistent family of criteria $\boldsymbol{F}$. The set of $\boldsymbol{A}$ can be defined directly in the form of a complete list or indirectly in the form of certain rules and formulas that determine feasible actions / variants / solutions, e.g. in the form of constraints (Figueira et al., 2005; Steuer, 1986; Żak, 2005). The consistent family of criteria $\boldsymbol{F}$ should be characterized by the following features (Roy, 1990a; Vincke, 1992): it should provide a comprehensive and complete evaluation of $\boldsymbol{A}$, each criterion in $\boldsymbol{A}$ should have a specific direction of preferences (minimized - min or maximized $-\max$ ) and should not be related with other criteria in $\boldsymbol{F}$. The domain of each criterion in $\boldsymbol{F}$ should be disjoint with the domains of other criteria.

Multiple criteria decision problems require specific procedures, methods and decision-making / aiding tools to be solved. Multiple criteria decision making / aiding methods can be classified according to several criteria, including the manner of the preference aggregation (Figueira et al., 2005; Vincke, 1992). According to this classification criterion one can distinguish:

- the methods of American inspiration, based on the utility function (e.g. AHP (Saaty, 1980), UTA (Jacquet-Lagreze and Siskos, 1982),

- the methods of the European / French origin, based on the outranking relation (e.g. Electre methods (Figueira et al., 2005; Roy, 1990b; Vincke, 1992), Promethee I and II (Brans et al., 1986).

B. Roy (Roy, 1990a) and J. Figueira and others (Figueira et al., 2005) distinguish four major stages of the solution procedure of the multiple criteria decision problems:

- recognition of the category of the decision problem,

- formulation of the decision problem - definition of variants, criteria and the model of the DM's preferences,

- selection of computer-based methods capable of solving the considered decision problem,

- computational experiments that involve the modelling and aggregation of the DM's preferences (synthesis of the global model of preferences) and result in the selection of the most desired solution.

Solving a multiple criteria decision problem consists in finding $a(n)$ action / variant / solution $\boldsymbol{x}$ in $\boldsymbol{A}$ (in the decision space for multiple objective optimization problems) which image in the objective (criteria) space $\boldsymbol{z}^{\boldsymbol{x}}$ generates the most desired values of the objective function $\boldsymbol{f}(\boldsymbol{x})$ (Steuer, 1986; Vincke, 1992; Żak, 2005). The 
image of a solution $\boldsymbol{x}$ in the objective space is a point $z^{x}=\left[z_{1}^{x}, \ldots, z_{J}^{x}\right]=f(x)$, such that $z_{j}^{x}=\boldsymbol{f}_{j}(\mathbf{x})$, for $j=1, \ldots, J$. Important notions in MCDM/A context are: the dominance relation and the Pareto-optimal (efficient) solution that refer to optimality in a multiple objective sense. Point $\boldsymbol{z}^{1}$ dominates $z^{2}, \boldsymbol{z}^{1} \boldsymbol{z}^{2}$, if $z_{j}^{1} \geqslant z_{j}^{2}$ and $z_{j}^{1}>z_{j}^{2}$ for at least one $j$. Solution $\boldsymbol{x}^{1}$ dominates $\boldsymbol{x}^{2}$ if the image of $\boldsymbol{x}^{1}$ dominates the image of $x^{2}$ in the objective space. A solution $x \in A$ is Paretooptimal (efficient) if there is no $x^{\prime} \in A$ that dominates $\boldsymbol{x}$. Point being an image of a Paretooptimal solution in the objective space is called non-dominated. The set of all Paretooptimal solutions is called the Paretooptimal set. The image $N D$ of the Paretooptimal set in the objective space is called the non-dominated set or Pareto front (Steuer, 1986; Vincke, 1992; Żak, 2005).

While searching for the best compromise solution in multiple criteria decision problems the DM may be interested in knowing the range of the criteria values in the Pareto-optimal set. The dispersion of the criteria values is given by two virtual points, called an ideal and a nadir point. The ideal point is represented by coordinates $\left(\boldsymbol{z}_{j}^{*}\right)$ characterized by the maximum values of all criteria $j \boldsymbol{z}_{j}^{*}=\max \boldsymbol{f}_{\boldsymbol{j}}(\boldsymbol{x})$, while the nadir point is represented by coordinates $\left(\boldsymbol{z}_{\boldsymbol{j}}\right)$ characterized by the minimum values of all criteria $j \hat{z_{j}}=\min \boldsymbol{f}_{j}(\boldsymbol{x})$.

MCDM/A methodology (Figueira et al., 2005; Roy, 1990a; Vincke, 1992; Zak, 2002; Żak, 2005): clearly identifies the major participants of the decision making/aiding process, such as: the decision maker (DM), the analyst and the interveners (stakeholders) and describes their roles in this process. The DM (an individual or a group of individuals) defines the objectives of the decision process, expresses preferences (Roubens, 1982) and finally evaluates the results generated. The analyst, who is external to the decision problem, handles the decision making / aiding process and supports the DM during its course. His / her role is to construct a decision model and suggest the most appropriate tools and methods in order to advance the DM in solving the decision problem. The analyst explains the consequences of certain actions / solutions to the DM and finally recommends the most desired one. The interveners, frequently called stakeholders, represent different individuals, organizations and groups that are interested in generating a rational solution to a certain decision problem. In many decision situations they express their own preferences and present concrete stand points that should be taken into account while analysing the decision problem. The final decision usually has a strong impact on the satisfaction of the interveners' interests.

\section{CASE STUDIES -}

\section{PRACTICAL APPLICATIONS OF MCDM/A METHODOLOGY IN SOLVING DECISION PROBLEMS IN LOGISTICS SYSTEMS}

3.1. Case study 1 - Single and bi - criterion optimization of the distribution system (Hapke et al., 2002; Żak, 2010; Żak et al., 2000)

The first case study focuses on the redesign of the distribution system for an international company based in Warsaw, Poland. The primary concern of the project is to define the number and the location of the warehouses as well as the service area of each warehouse. The considered distribution system is managed by the manufacturer 
of cosmetics, detergents and washing articles. The annual turnover of the company is roughly 100 million Euro (400 million Polish zloty - PLN). The company's major focus is the enhancement of the level of customer service and the reduction of distribution costs. The company's top management wants to redesign the distribution system and transform it into a more reliable and flexible one. The existing distribution system is based on two production plants and two warehouses located in cities A and B, next to the production facilities. Due to the fact that the production profile and the product portfolio are different in the production plants in A and B trunking between warehouses is required. It guarantees 48 hour deliveries in the majority of cases. The customer service level (defined as a product availability percentage) is 95\%. Customers are not satisfied with the timeliness and frequency of deliveries.

The decision problem is formulated in terms of multiple objective mathematical programming with binary and continuous variables.

Data. The following data is used in the model:

$I$ - the number of potential locations of warehouses,

$J$ - the number of regions that have to be assigned to the warehouses,

$D A_{j}$ - annual demand of region $j$ for products of production plant $A$ in [pallets], $j=1, \ldots, J$,

$D B_{j}$ - annual demand of region $j$ for products of production plant $B$ in [pallets], $j=1, \ldots, J$,

$T C_{i j}$ - average transportation cost from warehouse at location $i$ to region $j$ in $[\mathrm{PLN} /$ pallet], $i=1, \ldots, I, j=1, \ldots, J$,

$T C A_{j}$ - average transportation cost from production plant $A$ to warehouse at location $i$ in $[\mathrm{PLN} /$ pallet], $i=1, \ldots, I$,

$T C B_{j}$ - average transportation cost from production plant $B$ to warehouse at location $i$ in $[\mathrm{PLN} /$ pallet], $i=1, \ldots, I$,

$T T_{i j}$ - average travel time from warehouse at location $i$ to the first customer in region $j$ in $[\min ], i=1, \ldots, I, j=1, \ldots, J$,

$\mathrm{PHC}_{i}-$ cost of pallet handling in warehouse at location $i, i=1, \ldots, I$,

$C R T$ - current average pallet rotation time in [days], i.e. the average number of days that a pallet spends in the current distribution system,

$C C A$ - average daily cost of capital in stock per pallet produced in production plant $A$ in $[\mathrm{PLN} /$ day $]$,

$C C B$ - average daily cost of capital in stock per pallet produced in production plant $B$ in $[\mathrm{PLN} /$ day $]$,

$M C C_{i}-$ minimum annual cost of capital in stock in warehouse at location $i$ related to the safety stock of pallets,

$M L$ - maximum load of vehicles used for transportation from production plants to warehouses,

$D Y$ - average number of working days in a year. 
Decision variables. Two groups of decision variables are considered:

$y_{i}\{0,1\}, i=1, \ldots, I$, equals to one if warehouse at location $i$ is included in the plan, and 0 otherwise.

$x_{i j}\{0,1\}, i=1, \ldots, I, j=1, \ldots, J$, equals to one if region $j$ is assigned to warehouse at location $i$, and 0 otherwise.

Constraints. The first group of constraints assures that regions are assigned only to warehouses included in the plan:

$$
x_{i j} \leqslant y_{i} i=1, \ldots, I, j=1, \ldots, J
$$

The second group of constraints assures that each region is assigned to exactly one warehouse:

$$
\sum_{i=1}^{I} x_{i j}=1 j=1, \ldots, J
$$

Some additional constraints added to the model in order to obtain a linear model are described below.

Objective functions. Two objectives are considered in the model:

$T D C$ - total annual cost of distribution,

$M R T$ - maximum riding time to the first customer on a route.

Both objectives are minimized.

The first objective is defined in the following way:

$$
T D C=T T C+T P H C+T C C
$$

where:

$T T C$ - total annual transportation cost,

$T P H C$ - total annual cost of pallets handling in the warehouses,

$T C C$ - total annual cost of capital in stock.

The total annual transportation cost takes into account transportation from production plants to warehouses and transportation from warehouses to the customers in the regions. It is defined in the following way:

$$
\begin{aligned}
T T C & =\sum_{i=1}^{I} y_{i}\left(T C A_{i} \sum_{j=1}^{J} x_{i j} D A_{j}+T C B_{i} \sum_{j=1}^{J} x_{i j} D B_{j}\right)+ \\
& +\sum_{i=1}^{I} \sum_{j=1}^{J} x_{i j} T C_{i j}\left(D A_{j}+D B_{j}\right)
\end{aligned}
$$

Total annual cost of pallets handling in the warehouses is defined in the following way:

$$
T P H C=\sum_{i=1}^{I} y_{i} P H C_{i}\left(\sum_{j=1}^{J} x_{i j} D A_{j}+\sum_{j=1}^{J} x_{i j} D A_{j}\right)
$$


Total annual cost of capital in stock is defined in the following way:

$$
\begin{array}{r}
T C C=\sum_{i=1}^{I} y_{i} \max \left\{M C C_{i}, \sum_{j=1}^{J} x_{i j} D A_{j} C C A\left(C R T+D H A_{i}\right) \times\right. \\
\left.\times \sum_{j=1}^{J} x_{i j} D B_{j} C C B\left(C R T+D H B_{i}\right)\right\}
\end{array}
$$

where $D H A_{i}$ and $D H B_{i}$ is an average headway of deliveries for production plants $A$ and $B$, respectively, defined in the following way:

$$
\begin{aligned}
& D H A_{i}=M L /\left(\sum_{j=1}^{J} x_{i j} D A_{j} / D Y\right) \\
& D H B_{i}=M L /\left(\sum_{j=1}^{J} x_{i j} D B_{j} / D Y\right)
\end{aligned}
$$

Total annual cost of capital in stock is not linear as it uses operator max. In order to obtain a linear model we add $\boldsymbol{I}$ continuous variables $c c_{i}$ interpreted as cost of capital in stock in warehouse at location $\boldsymbol{i}$. Furthermore, we add two groups of constraints:

$$
\begin{gathered}
c c_{i} \geqslant M C C_{i} i=1, \ldots, I \\
c c_{i} \geqslant \sum_{j=1}^{J} x_{i j} D A_{j} C C A\left(C R T+D H A_{i}\right)+ \\
+\sum_{j=1}^{J} x_{i j} D B_{j} C C B\left(C R T+D H B_{i}\right) i=1, \ldots, I
\end{gathered}
$$

Total annual cost of capital in stock is defined as:

$$
T C C=\sum_{i=1}^{I} y_{i} c c_{i}
$$

Maximum riding time to the first customer on a route is defined in the following way:

$$
M R T=\max \left\{x_{i j} T T_{i j}\right\}
$$

Again, this objective is not linear. In order to obtain linear model we add a continuous variable $m r t$ and the following group of constraints:

$$
m r t \geqslant x_{i j} T T_{i j} i=1, \ldots, I, j=1, \ldots, J
$$

Maximum riding time to the first customer on a route is then equal to a new variable:

$$
M R T=m r t
$$


Finally, we obtain a mixed binary bi-objective mathematical programming problem with $I \cdot J+J$ binary variables and $I+1$ continuous variables defined in the following way:

- minimize:

$$
T C C=\sum_{i=1}^{I} y_{i} c c_{i}
$$

- minimize:

$$
M R T=m r t
$$

- subject to:

$$
\begin{gathered}
x_{i j} \leqslant y_{i} i=1, \ldots, I, j=1, \ldots, J \\
\sum_{i=1}^{I} x_{i j}=1 j=1, \ldots, J \\
c c_{i} \geqslant M C C_{i} i=1, \ldots, I \\
c c_{i} \geqslant \sum_{j=1}^{J} x_{i j} D A_{j} C C A\left(C R T+D H A_{i}\right)+\sum_{j=1}^{J} x_{i j} D B_{j} C C B\left(C R T+D H B_{i}\right) i=1, \ldots, I \\
D H A_{i}=M L /\left(\sum_{j=1}^{J} x_{i j} D A_{j} / D Y\right) \\
D H B_{i}=M L /\left(\sum_{j=1}^{J} x_{i j} D B_{j} / D Y\right) \\
m r t \geqslant x_{i j} T T_{i j} i=1, \ldots I, j=1, \ldots, J \\
y_{i} \in\{0,1\} i=1, \ldots, I \\
x_{i j} \in\{0,1\} i=1, \ldots, I, j=1, \ldots, J
\end{gathered}
$$

In the analysed case $J=39, I=49$, thus the problem has 1900 binary variables and 50 continuous variables.

3.2. Case study 2 - Multiobjective ranking of the warehouses - distribution centres (Żak and Sawicki, 2000)

Company A analysed in case study 2 is one of the Polish distributors of spare parts for motor-vehicles. The set of 11 existing warehouses constitutes the infrastructure of the company's logistics system. All warehouses are dispersed all over. Company A is in financial troubles, which is demonstrated by the following characteristics: high level of inventory ( $71 \%$ of circulating capital) and the resulting locked-up capital as well as negative profitability of sales $(-6.8 \%)$. 
As indicated by G. Forger (Forger, 1998) the benchmark analysis of the warehouses distribution centres had been performed. The detailed financial data of the whole logistics system proved that 5 of the warehouses are not profitable at all. In such circumstances, company's A management is very interested in a comprehensive, system-oriented analysis and evaluation of all warehouses constituting the infrastructure of the overall distribution system. The warehouses are to be ranked from the best to the worst based on the analysis of different technical, economical and organizational aspects.

The set of alternatives $(\boldsymbol{A})$ is composed of 11 existing warehouses, located in different cities in and denominated as follows: B1, B2, B3, G1, L1, L2, O1, O2, O3, S1, T1. All alternatives differ between each other substantially. Their warehousing area ranges from $320 \mathrm{~m}^{2}$ to $3,620 \mathrm{~m}^{2}$, and the warehouse buildings height ranges from 3 to 16 meters. The smallest warehouse employs 4 workers, while the largest one has 86 employees. The warehouses also differ in terms of the material flow generated by each unit and the inventory holding costs. The annual material flow ranges from 415,000 PLN to $17,000,000$ PLN and the annual holding costs range from 27,913 to 467,422 PLN. One can also recognize differences among the considered alternatives in terms of internal temperature, utilized equipment and their construction.

A consistent family $(\boldsymbol{F})$ of 11 criteria denominated by $f_{1}$ to $f_{11}$ is used to evaluate the usefulness and attractiveness of each warehouse in the distribution system. The family $F$ is composed of four groups of criteria. Criteria: $f_{1}$ to $f_{5}$, focused on the improvement of financial and organizational indicators of each warehouse, represent the expectations of the company's A management team. Criteria: $f_{8}$ to $f_{10}$ represent the employees perspective and assures appropriate working and social conditions. Criterion $f_{11}$ tends to fulfil customers' expectations and provide high level of customer service. Criteria $f_{6}$ and $f_{7}$ represent the common interests of different stakeholders (workers, management team and customer).

The family $\boldsymbol{F}$ includes:

- Warehouses utilization index $-\boldsymbol{f}_{\mathbf{1}}$, defined as an absolute value of the difference between the most desired utilization ( $85 \%$ is assumed to be the ideal value defined by the decision maker) and the real value measured in a certain warehouse. The criterion is minimized.

- Fork-lifts utilization index $-\boldsymbol{f}_{\mathbf{2}}$, is an absolute value of the difference between the optimal and the real number of fork-lifts in a certain warehouse. The criterion is minimized.

- Material flow per warehouse employee $-f_{3}$, is a quotient of the annual monetary value of the material flow and a number of warehouse employees. The value of this criterion (expressed in PLN per worker) indicates the utilization of human resources and the productivity of each warehouse. The criterion $f_{3}$ is maximized.

- Warehouse turnover per square metre $-f_{4}$, is a quotient of the annual monetary value of the material flow and the warehouse area. The value of this criterion (expressed in PLN per square metre) indicates the efficiency of the warehousing space management. Criterion $f_{4}$ is maximized. 
- Holding cost per square metre $-\boldsymbol{f}_{\mathbf{5}}$, is a quotient of annual cost of warehousing and the warehouse area. Criterion $f_{5}$ (expressed in PLN per square metre) is minimized.

- Modernity of the warehouse $-\boldsymbol{f}_{\mathbf{6}}$, is a criterion defined by the age of the warehouse. It is assumed that the younger the warehouse the more efficient organizational principles and equipment it utilizes. Thus, criterion $f_{6}$ is minimized.

- Structure of the warehouse building $-\boldsymbol{f}_{\mathbf{7}}$, is defined by a number of points allocated by experts to each warehouse building for its structure characteristics. The criterion is maximized.

- Internal temperature in July $-f_{8}$ and internal temperature in January - $\boldsymbol{f}_{\mathbf{9}}$ are defined by a number of points allocated to each warehouse for maintaining inside the warehouse building a certain standard temperature in the summer and winter season, respectively. Both criteria are maximized.

- Working conditions in the warehouse $-\boldsymbol{f}_{\mathbf{1 0}}$. This criterion is defined by a number of points allocated by experts to each warehouse for the provision of facilities, equipment and social solutions that enhance comfort of work. Criterion $f_{10}$ is maximized.

- Customer satisfaction - $\boldsymbol{f}_{\mathbf{1 1}}$, is defined by a number of points allocated by a sample of customers and experts to each warehouse for the provision of a certain level of convenience to a customer, including: location of the customer service office, warehouse accessibility, dispersion and integrity. The criterion is maximized.

\section{COMPUTATIONAL EXPERIMENTS}

\subsection{Case study 1 (Hapke et al., 2002; Żak, 2010; Żak and Sawicki, 2000)}

In case study 1 the optimization of the distribution system was performed with the application of the extended version of MS Excel Solver - Premium Solver Plus by Frontline Systems. It solves linear problems composed of up to 2,000 variables and 400 constraints. The experiments were divided into two steps: the first one, based on single objective optimization and the second one focused on bi-objective optimization.

In the first step, only one objective - total distribution costs - was used, to demonstrate the comparison between the existing and the optimal distribution systems (see Table 1). As one can see the optimal system is composed of 7 warehouses.

Table 1. The comparison between the existing and the optimal distribution system (single objective optimization)

\begin{tabular}{|c|c|c|c|}
\hline $\begin{array}{c}\text { Distribution } \\
\text { system }\end{array}$ & $\begin{array}{c}\text { Number of } \\
\text { warehouses }\end{array}$ & $\begin{array}{c}\text { Total annual } \\
\text { distribution } \\
\text { costs [PLN] }\end{array}$ & $\begin{array}{c}\text { Ridig time } \\
\text { [h:mm] }\end{array}$ \\
\hline Existing & 2 & $9,924,300$ & $09: 22$ \\
\hline Optimal & 7 & $9,357,784$ & $06: 09$ \\
\hline
\end{tabular}


An interesting observation is that single objective optimization resulted in reducing both total distribution costs (by 566,516 PLN) and the riding time (by 3 hours and 13 minutes). Thus from the multiple objective point of view the optimal distribution system dominates the current one. As a result of the optimization process new definition of service areas (new assignment of 49 regions to 7 warehouses) for each warehouse was obtained.

In the bi-objective optimization $\varepsilon$-constraints method (Steuer, 1986; Figueira et al., 2005) were used to generate a representative sample of Pareto-optimal solutions. In the computational procedure riding time was constrained from to 2 hours. The result of the bi-objective optimization is the set of Pareto-optimal distribution systems presented in Figure 1. The generated distribution systems are composed of 7-23 warehouses. The results show the existing cost-time trade-offs. For instance, riding time reduction from 6:09 to 5:23 (by $46 \mathrm{~min}$ ) results in 2 more warehouses in the distribution system and additional costs of 186,000 PLN, while riding time reduction from 2:44 to 2:41 (by $3 \mathrm{~min}$ ) also results in 2 additional warehouses in the distribution system and a corresponding increase in total distribution costs of 548,000 PLN.

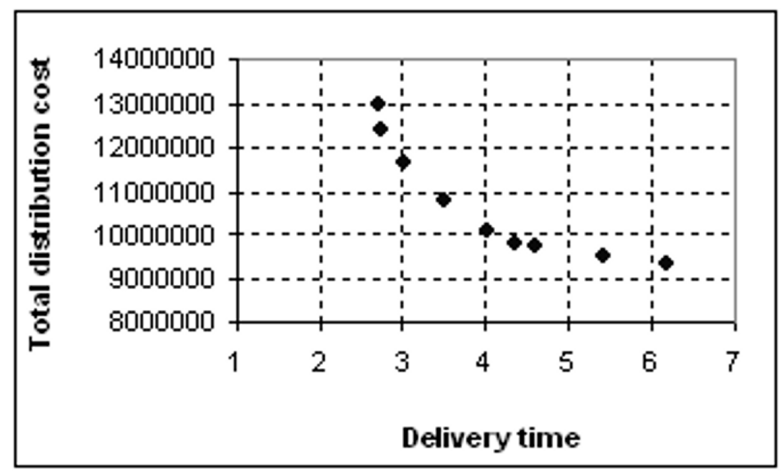

\begin{tabular}{|c|c|c|}
\hline Riding time [h:mm] & Total distribution costs [PLN] & No. of warehouses \\
\hline $02: 41$ & $12,972,507$ & 23 \\
\hline $02: 44$ & $12,424,210$ & 21 \\
\hline $02: 59$ & $11,653,423$ & 18 \\
\hline $03: 28$ & $10,813,246$ & 15 \\
\hline $04: 00$ & $10,090,964$ & 12 \\
\hline $04: 20$ & $9,802,832$ & 10 \\
\hline $04: 35$ & $9,746,413$ & 10 \\
\hline $05: 23$ & $9,543,711$ & 9 \\
\hline $06: 09$ & $9,357,784$ & 7 \\
\hline
\end{tabular}

Fig. 1. Pareto-optimal set of the distribution systems in the numerical and graphical form

Another interesting observation comes from the comparison of the existing distribution system (see Table 1) with a set of Pareto-optimal distribution systems (see Figure 1). Maintaining the same level of total distribution costs (around 9,900,000 PLN) 
one can replace the existing distribution system (with 2 warehouses) by the Pareto - optimal one (with 10 warehouses) and shorten the riding time from to less than (a 55\% reduction). The distribution system with 10 warehouses has been finally selected as the most desired option and practically implemented.

\subsection{Case study 2 (Żak and Sawicki, 2000)}

In case study 2 the computational experiment was carried out with the application of the original software package ELECTRE III/IV (Figueira et al., 2005; Vincke, 1992; Żak, 2005). The computational procedure was preceded by the definition of the matrix of performances which comprises the evaluation of each alternative by each criterion (see Table 2). In addition, the DM's preference model was constructed with the application of indifference $\boldsymbol{q}_{\boldsymbol{j}}$, preference $\boldsymbol{p}_{\boldsymbol{j}}$, veto $\boldsymbol{v}_{\boldsymbol{j}}$ thresholds and the weight $\boldsymbol{w}_{\boldsymbol{j}}$, defined for each criterion (see Table 3 ). The computational procedure starts with the calculation of concordance indicators $\boldsymbol{C}(\boldsymbol{a}, \boldsymbol{b})$ for each pair of alternatives $\boldsymbol{a}$ and $\boldsymbol{b}$ and presented as a concordance matrix (see Table 4$). \boldsymbol{C}(\boldsymbol{a}, \boldsymbol{b})$ expresses the extent to which the scores of $\boldsymbol{a}$ and $\boldsymbol{b}$ on all criteria are in concordance with the proposition $\boldsymbol{a}$ outranks $\boldsymbol{b}$. Next, the discordance index $\boldsymbol{D}_{\boldsymbol{j}}(\boldsymbol{a}, \boldsymbol{b})$ is calculated for each criterion $\boldsymbol{j}$, taking into account arguments represented by the values of criteria for which one can not accept the statement the $\boldsymbol{a}$ outranks $\boldsymbol{b}$. Finally, the outranking relation $\boldsymbol{S}$ is constructed. $\boldsymbol{S}$ indicates the extent to which "a outranks b" overall. It is expressed by the degree of credibility $\boldsymbol{d}(\boldsymbol{a}, \boldsymbol{b})$. Further details of the computational algorithm applied in Electre III/IV method can be found in (Figueira et al., 2005; Vincke, 1992; Żak, 2005).

Table 2. The matrix of performances for 11 warehouses

\begin{tabular}{|c|c|c|c|c|c|c|c|c|c|c|c|c|c|}
\hline \multirow{2}{*}{ No. } & \multirow{2}{*}{$\begin{array}{l}\text { Family of } \\
\text { criteria } F\end{array}$} & \multirow{2}{*}{ Unit } & \multicolumn{11}{|c|}{ Set of alternatives $A$} \\
\hline & & & B1 & B2 & B3 & G1 & L1 & L2 & O1 & $\mathrm{O} 2$ & O3 & S1 & T1 \\
\hline 1 & $\begin{array}{l}\text { Warehouse } \\
\text { utilization } \\
\text { index }-f_{1}\end{array}$ & $\%$ & 5 & 0 & 13 & 15 & 15 & 65 & 15 & 33 & 5 & 15 & 13 \\
\hline 2 & $\begin{array}{c}\text { Fork-lifts } \\
\text { utilization } \\
\text { index }-f_{2} \\
\end{array}$ & - & 0 & 0 & 0 & 1 & 1 & 0 & 1 & 0 & 0 & 0 & 1 \\
\hline 3 & $\begin{array}{c}\text { Material } \\
\text { flow per } \\
\text { warehouse } \\
\text { employee }-f_{3}\end{array}$ & $\begin{array}{c}\text { thou } \\
\text { PLN } \\
\text { per } \\
\text { worker }\end{array}$ & 182.2 & 196.7 & 111 & 99.8 & 106.6 & 165 & 103.9 & 122.5 & 103.6 & 135.8 & 98.1 \\
\hline 4 & $\begin{array}{l}\text { Warehouse } \\
\text { turnover per } \\
\text { sq. } \mathrm{m}-f_{4}\end{array}$ & $\begin{array}{l}\text { thou } \\
\text { PLN } \\
\text { per } \\
\text { sq. m }\end{array}$ & 19.3 & 47 & 22.2 & 26.9 & 7.1 & 14.1 & 8.3 & 19.8 & 6.9 & 24.9 & 17.8 \\
\hline 5 & $\begin{array}{l}\text { Holding cost } \\
\text { per sq. } \mathrm{m}-\mathrm{f} 5\end{array}$ & $\begin{array}{c}\text { PLN } \\
\text { per } \\
\text { sq. } m \\
\end{array}$ & 42 & 130 & 47 & 100 & 37 & 50 & 59 & 71 & 24 & 115 & 52 \\
\hline
\end{tabular}


Table 2 cont.

\begin{tabular}{|c|c|c|c|c|c|c|c|c|c|c|c|c|c|}
\hline \multirow{2}{*}{ No. } & \multirow{2}{*}{$\begin{array}{l}\text { Family of } \\
\text { criteria } F\end{array}$} & \multirow{2}{*}{ Unit } & \multicolumn{11}{|c|}{ Set of alternatives $A$} \\
\hline & & & B1 & B2 & B3 & G1 & L1 & L2 & O1 & $\mathrm{O} 2$ & O3 & S1 & $\mathrm{T} 1$ \\
\hline 6 & $\begin{array}{l}\text { Modernity } \\
\text { of the } \\
\text { warehouse } \\
\quad-f_{6}\end{array}$ & - & 20 & 1 & 60 & 10 & 30 & 20 & 20 & 17 & 10 & 8 & 10 \\
\hline 7 & $\begin{array}{c}\text { Structure } \\
\text { of the } \\
\text { warehouse } \\
\text { building }-f_{7}\end{array}$ & points & 2.5 & 2.5 & 0 & 5 & 7.5 & 15 & 5 & 15 & 1 & 5 & 5 \\
\hline 8 & $\begin{array}{c}\text { Internal } \\
\text { temperature } \\
\text { in July }-f_{8}\end{array}$ & points & 0 & 0 & 0 & 0 & 15 & 15 & 0 & 0 & 0 & 15 & 0 \\
\hline 9 & $\begin{array}{c}\text { Internal } \\
\text { temperature } \\
\text { in January } \\
-f_{9}\end{array}$ & points & 0 & 0 & 15 & 0 & 0 & 15 & 15 & 15 & 0 & 15 & 0 \\
\hline 10 & $\begin{array}{l}\text { Working } \\
\text { conditions } \\
\text { in the } \\
\text { warehouse } \\
-f_{10}\end{array}$ & points & 2 & 4 & 7.5 & 5 & 10.5 & 13 & 6 & 7.5 & 2 & 7 & 1.5 \\
\hline 11 & $\begin{array}{l}\text { Customer } \\
\text { satisfaction } \\
-f_{11}\end{array}$ & points & 11 & 9 & 7 & 5 & 8 & 10 & 2 & 10 & 9 & 14 & 3 \\
\hline
\end{tabular}

Table 3. The model of DM's preferences

\begin{tabular}{|c|c|c|c|c|c|c|c|}
\hline \multirow{2}{*}{ No. } & \multirow{2}{*}{$\begin{array}{l}\text { Family of } \\
\text { criterion } F\end{array}$} & \multirow{2}{*}{ Unit } & \multicolumn{5}{|c|}{ Parameters } \\
\hline & & & $q_{j}$ & $p_{j}$ & $v_{j}$ & $w_{j}$ & $d p_{j}{ }^{*}$ \\
\hline 1 & $\begin{array}{c}\text { Warehouse } \\
\text { utilization index }-f_{1}\end{array}$ & $\%$ & 10 & 20 & 35 & 10 & $\min$ \\
\hline 2 & $\begin{array}{l}\text { Fork-lifts utilization } \\
\text { index }-f_{2}\end{array}$ & - & 0.1 & 0.5 & 2 & 5 & $\min$ \\
\hline 3 & $\begin{array}{c}\text { Material flow per } \\
\text { warehouse employee }-f_{3}\end{array}$ & $\begin{array}{l}\text { thou PLN } \\
\text { per worker }\end{array}$ & 10 & 30 & 50 & 2 & $\max$ \\
\hline 4 & $\begin{array}{l}\text { Warehouse turnover } \\
\text { per sq. } \mathrm{m}-f_{4}\end{array}$ & $\begin{array}{l}\text { thou PLN } \\
\text { per sq. m }\end{array}$ & 1 & 10 & 20 & 5 & $\max$ \\
\hline 5 & $\begin{array}{l}\text { Holding cost per } \\
\quad \text { sq. } \mathrm{m}-f_{5}\end{array}$ & zł per sq. m & 10 & 40 & 70 & 5 & $\min$ \\
\hline
\end{tabular}


Table 3 cont.

\begin{tabular}{|c|c|c|c|c|c|c|c|}
\hline 6 & $\begin{array}{c}\text { Modernity of the } \\
\text { warehouse }-\mathrm{f} 6\end{array}$ & - & 5 & 20 & 40 & 2 & $\min$ \\
\hline 7 & $\begin{array}{c}\text { Structure of the } \\
\text { warehouse building }-\mathrm{f} 7\end{array}$ & points & 1 & 3 & 7 & 2 & $\max$ \\
\hline 8 & $\begin{array}{c}\text { Internal temperature } \\
\text { in July }-f_{8}\end{array}$ & points & 1 & 5 & 20 & 5 & $\max$ \\
\hline 9 & $\begin{array}{c}\text { Internal temperature } \\
\text { in January }-f_{9}\end{array}$ & points & 1 & 5 & 20 & 5 & $\max$ \\
\hline 10 & $\begin{array}{c}\text { Working conditions in } \\
\text { the warehouse }-f_{10}\end{array}$ & points & 2 & 4 & 7 & 10 & $\max$ \\
\hline 11 & $\begin{array}{c}\text { Customer } \\
\text { satisfaction }-f_{11}\end{array}$ & points & 1 & 2 & 4 & 10 & $\max$ \\
\hline
\end{tabular}

${ }^{*} d p_{j}-$ direction of preferences

In the third step of the computational procedure the outranking relation is utilized to perform the descending and ascending distillations, which result in two complete pre-orders of all alternatives (see Figure 2). Ultimately, the final ranking is computed as an intersection of two pre-orders (see Figure 3).

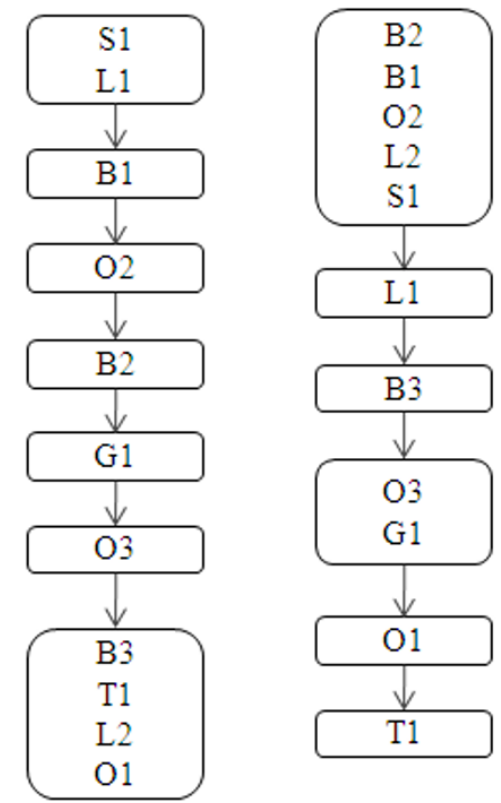

Fig. 2. Descending and ascending distillations

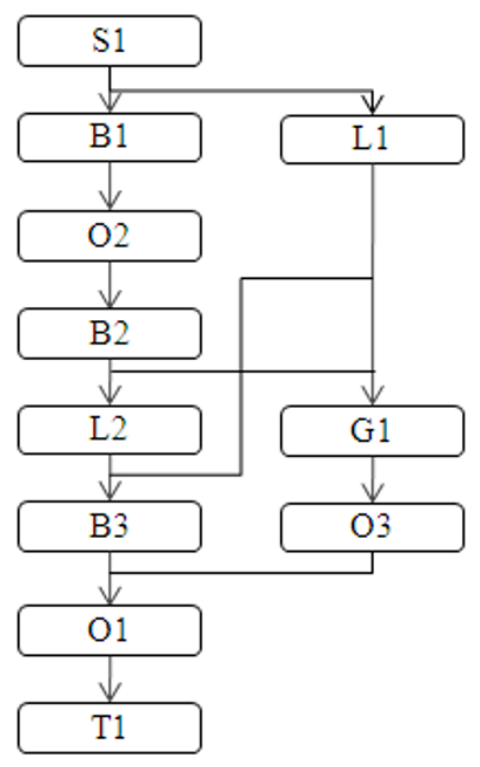

Fig. 3. Final ranking of warehouses 
If the alternatives on the final graph are connected by an arrow, the upper alternative outranks the lower one. Indifferent alternatives are displayed in the same box. Incomparable alternatives are not connected by arrows and are displayed in separate boxes.

Based on the results of the final ranking one can draw the following conclusions:

- Three warehouses: S1, B1 and L1 (top part of the ranking) constitute the set of most desirable alternatives; two other warehouses - O1 and T1 (bottom part of the ranking) are the worst alternatives.

- The leaders of the ranking are characterized by the following features: S1 is in a good technical condition and has appropriate warehouse equipment (criteria $f_{7}$ and $f_{2}$ ). It is characterized by a good internal temperature (criteria $f_{8}$ and $f_{9}$ ) as well as high organizational efficiency (criteria $f_{3}$ and $f_{4}$ ). Finally, S1 provides an excellent customer service (criterion $f_{11}$ ).

- Warehouse B1 is equipped with appropriate technical devices. In particular it has a very good fork-lifts utilization index (criterion $f_{2}$ ). It is also characterized by an excellent (near optimal) warehouse utilization - criterion $f_{1}$ and utilization of human resources - criterion $f_{3}$. In addition, warehouse B1 generates, relatively low operating costs, resulting in acceptable level of material holding costs - criterion $f_{5}$. Similarly to S1, B1 provides a high customer service level (criterion $f_{11}$ ).

Warehouse L1 is considered to be a well-managed and organized warehouse. It has low holding cost (criterion $f_{5}$ ) and a satisfactory material flow per warehouse employee (criterion $f_{3}$ ).

\section{CONCLUSIONS}

The paper presents the theoretical background and practical application of MCDM/A techniques to the evaluation and redesign of logistics systems. In the presented case studies, classical decision aiding methodology is demonstrated, including: recognition of the category of the multiple criteria decision problem, formulation of the mathematical model - definition of variants, criteria and the model of the DM's preferences, selection of computer-based methods capable of solving the considered decision problems, computational experiments resulting in the selection of the most desired solutions.

Two different problems arising in the logistics systems have been presented:

- In case study I, the redesign of the distribution system, formulated as a single and bi-objective mathematical programming problem (multiple criteria choice problem);

- In case study II the evaluation of the logistics infrastructure, considered as a multiple criteria ranking problem in which variants - warehouses have been evaluated by a consistent family of criteria and finally ranked from the best to the worst.

The article demonstrates the application of different MCDM/A techniques: bi-objective optimization (also compared with single objective optimization) and multiple criteria ranking methods. It has been proved that the MCDM/A methodology can 
be effectively applied both to the redesign (optimization) of the logistics system as well as the evaluation of usefulness and attractiveness of warehouses in such systems. The presented approach is universal and can be applied in any physical distribution / logistics system with warehouses - distribution centres.

The paper shows the practical applicability of the proposed approach. In case study 1 the optimal distribution system is $6 \%$ more efficient than the existing one (cost-wise) and the finally selected Pareto-optimal distribution system provides an enhanced by $55 \%$ customer service (reduction of the delivery time). In case study 2 the following practical conclusions can be drawn:

- The company's A physical distribution system should be based on the most efficient and useful warehouses, such as: S1, B1, O2, B2, L2 because of their highest positions in the ranking,

- Three warehouses: T1, O1 and O3 (bottom positions in the final ranking) should be closed down. O1 has the worst technical-financial characteristics and it is the company's real pain. T1 should be integrated with B3 due to the fact that they are located very close to each other (45 km distance).

- Investment should be made in B2 and G1 to improve the structures of the warehouse buildings and the working conditions of the warehouses. Due to the fact that those warehouses generate high turnovers they should be the company's A model warehouses,

- More emphasise should be placed on the financial efficiency of warehouse S1. As the leader of the ranking (due to its technical and organizational characteristics) it requires more careful financial planning and cost rationalization,

- Warehouse L2 should be considered as a central warehouse (all-Polish distribution centre). This warehouse has an excellent location. It requires however substantial investment in equipment which would probably be returned if the material flow through the warehouse was sufficiently high.

\section{REFERENCES}

Brans, J., Vincke, P., Mareschal, B., 1986. How to Select and How to Rank Projects: The PROMETHEE Method. European Journal of Operational Research, 24, pp. 228-238.

Coyle, J.J., Bardi, E.J., Langley Jr., J., 1996. The Management of Business Logistics. West Publishing Company, St. Paul.

Figueira, J., Greco, S., Ehrgott, M. (eds.), 2005. Multiple Criteria Decision Analysis. State of the Art Surveys. Springer, New York.

Forger, G., 1998. Benchmark Your Warehouse for Future Success. Special Report. Modern Materials Handling, 10, pp. 39-41.

Hapke, M., Jaszkiewicz, A., Zak, J., 2002. The Design of the Physical Distribution System with the Application of the Multiple Objective Mathematical Programming. Case Study. In: Trzaskalik T., Michnik J. (eds.), Multiple Objective and Goal Programming. Recent Developments. Advances in Soft Computing. Physica-Verlag, Heidelberg, pp. 297-309.

Hillier, F.S., Lieberman, G.J., 2005. Introduction to Operations Research. McGraw-Hill, New York. 
Jacquet-Lagreze, E., Siskos, J., 1982. Assessing a Set of Additive Utility Functions for Multicriteria Decision-Making, the UTA Method. European Journal of Operational Research, 10, pp. 151-164.

Kieffer, A.W., Novack, R.A., 1998. An Empirical Analysis of Warehouse Measurement Systems in the Context of Supply Chain Implementation. Transportation Journal, 38(3), pp. 18-26.

Kisperska-Moron, D., 1999. Warehousing Conditions for Holding Inventory in Polish Supply Chain. International Journal of Production Economics, 59, pp. 123-128.

Kopczak, L.R., 1997. Logistics Partnerships and Supply Chain Restructuring: Survey Results from the VS Computer Industry. Production and Operations Management, 6(3), pp. 226-247.

Korpela, J., Lehmusvaara, A., 1999. A Customer Oriented Approach to Warehouse Network Evaluation and Design. International Journal of Production Economics, 59, pp. 135-146.

Landers, T.L., Cole, M.H., Walker, B., Kirk, R.W., 2000. The Virtual Warehousing Concept. Transportation Research, 36E(2), pp. 115-125.

McKinnon, A., 1989. Physical Distribution Systems. Routledge, New York.

Ross, D.F., 1996. Distribution. Planning and Control. Kluwer Academic Publishers, Boston.

Roubens, M., 1982. Preference Relations on Actions and Criteria in Multicriteria Decision Making. European Journal of Operational Research, 10, pp. 51-55.

Rouwenhorst, B., Reuter, B., Strockrahm, G.J., Van Houtum, G.J., Mantel, R.J., Zijm, W.H.M., 2000. Warehouse Design and Control: Framework and Literature Review. European Journal of Operational Research, 122, pp. 515-533.

Roy, B., 1990a. Decision-Aid and Decision Making. European Journal of Operational Research, 45 , pp. $324-331$.

Roy, B., 1990b. The Outranking Approach and the Foundations of ELECTRE Methods. In: Bana e Costa C.A. (ed.), Readings in Multiple Criteria Decision Aid. Springer-Verlag, Berlin, pp. 155-183.

Saaty, T.L., 1980. The Analytic Hierarchy Process: Planning, Priority Setting, Resource Allocation. McGraw-Hill, New York.

Steuer, R., 1986. Multiple Criteria Optimization: Theory, Computation and Application. John Wiley \& Sons, New York.

Van den Berg, J.P., Zijm, W.H.M., 1999. Models for Warehouse Management: Classification and Examples. International Journal of Production Economics, 59, pp. 519-528.

Vincke, P., 1992. Multicriteria Decision-Aid. John Wiley \& Sons, Chichester.

Wegryn, G.W., Siprelle, A.J., 2001. Combined Use of Optimization and Simulation Technologies to Design an Optimal Logistics Network. Proceedings of the Annual Conference: Council of Logistics Management, Kansas City, 21 September - 3 October, CD Proceedings.

Zak, J., 2002. The MCDA Methodology Applied to Solve Complex Transportation Decision Problems. Proceedings of the 9th Meeting of the EURO Working Group on Transportation: Intermodality, Sustainability and Intelligent Transportation Systems, Bari, 10-13 June, pp. 685-693.

Żak, J., 2005. Wielokryterialne wspomaganie decyzji w transporcie drogowym. Wydawnictwo Politechniki Poznańskiej, Poznań. 
Żak, J., 2010. Application of Operations Research Techniques to the Redesign of the Distribution Systems. In: Dangelmaier W., Blecken A., Deluis R., Klopfer S. (eds.), Advanced Manufacturing and Sustainable Logistics. Springer, Lecture Notes in Business Information Processing, 46, pp. 57-72.

Żak, J., Redmer, A., Jaszkiewicz, A., 2000. Location Analysis of the Infrastructure in the Transportation System. Single and Bi-criterion Optimization. Proceedings of the $4^{\text {th }}$ International Workshop on Transportation Planning Methodologies for Developing Countries, Bombay, December 5-7, CD Proceedings.

Żak, J., Sawicki, P., 2000. The Multi-objective Ranking of the Warehouse in the Physical Distribution System. Proceedings of the $4^{\text {th }}$ International Workshop on Transportation Planning and Implementation Methodologies for Developing Countries: Transportation Infrastructure, Bombay, December 5-7, CD Proceedings.

Zak, J., Wlodarczak, H., Kicinski, M., 2002. The MCDM Based Redesign of the Distribution System. Proceedings of the 9th Meeting of the EURO Working Group on Transportation: Intermodality, Sustainability and Intelligent Transportation Systems, Bari, 10-13 June, pp. 665-670. 